\title{
Determination of Correlation Between Composition, Rolling Parameters and Mechanical Characteristics of the Hot Rolled Steels
}

\author{
PETRICA ALEXANDRU1*, BOGDAN GABRIEL CARP2 \\ 'Dunarea de Jos University of Galati, Department of Science and Materials Engineering, 111 Domneasca Str., 800201, Galati, \\ Romania \\ 2Dunarea de Jos University of Galati, Department of Thermal Systems and Environmental Engineering, 111 Domneasca Str., \\ 800201, Galati, Romania
}

\begin{abstract}
The controlled lamination of thick sheets involves the use of algorithms for choosing the rolling parameters: the initial heating temperature, the lamination scheme (the distribution of the total thickness reduction on each rolling cage, the number of passes through each cage and the distribution of the thickness reduction on each passage, intermediate cooling - cooling time and speed), and the temperature of the product obtained at the end of the rolling. The complexity of the phenomena, which occur during the hot plastic deformation process and which must be sufficiently well mastered in order to obtain reproducibly the technical specifications imposed on the products with different destinations, is the justification for this work. The data provided by Arcelor-Mittal Galati was used to obtain the mathematical model. Equations that correlate the main mechanical characteristics with the chemical composition of the steel and the parameters of the hot rolling pattern used are presented.
\end{abstract}

Keywords: controlled rolling steels, thick sheets, regression predictive equation, optimization hot rolling

The hot-rolled steel sheets represent a significant proportion, in quantitative terms, in all steel rolled products. Shipbuilding, petrochemical industries - pipelines and reactor vessels, power plants, heavy machinery industry, etc., are the most important destinations of these products. The main advantages that hot rolling in individual sheets, presents in relation to hot-rolled strips, is related to the range of thicknesses and widths that may be more extensive. The range of products covers a broad spectrum of chemical compositions and mechanical features.

Driving the rolling processes so that the plates obtained comply with the technical specifications, especially with regard to the mechanical properties, are based on the knowledge of the correlation between the chemical composition of the steels, the thermal evolution during the plastic deformation process and, the obvious, on the mechanical parameters of the this deformation and after reaching the final dimensions, also requires consideration of the cooling regime on the transfer route (cooling beds) or the final treatment (normalization, quenchingtempering, etc.). Establishing complex models of hot rolling processing, based on the description of the phenomena involved, by analytical equations, is unfortunately not possible at this time. Many researchers have made progress in designing algorithms for conducting hot rolling processes in steel so that, depending on the chemical composition, the desired mechanical properties can be obtained. To take into account the metallurgical processes involved in hot rolling, they use equations that model recrystallization [1], phase transformations [2] or mechanical properties [3]. These equations are practically empirical equations because they use correction coefficients depending on various situations (composition, temperature, etc.) All models used are regressive, some simple are based on linear or nonlinear regression equations [4,5], and some more appreciated using neural networks [6-8].

Most predictive models are limited to three mechanical characteristics: ultimate tensile strength, yield strength [9], elongation at break, chemical-related composition (typically more than 10 chemical elements), the slab heating temperature in furnace, temperature drop on the route from the roughing mill to the finishing, the reduction in thickness at the finishing mill, the end of rolling temperature and possibly the parameters of the controlled cooling or the final heat treatment, when it exists [10].

However, the use of neural networks is very useful because of the ability to capture the complex influences of variables with applications, for example in the case of new chemical compositions - which exceeds the original database, thus making it possible to extrapolate the influences, which corresponds, to a certain extent, learning in experiments and predicting results. By comparison, linear or nonlinear regression leads to empirical models that are not recommended for extrapolation. Basically regression-based models are only applicable to the description of the behavior of the dependent variable versus independent variables only on the variation domains, as it results from the experimental database used. Therefore, experiments for building such a database are numerous, especially in the case of a large number of independent variables and thus extremely costly if they are considered to be industrial scale experiments. However, for a mass industrial unit, the practical database that can be used is enriched with increasing the quantity and variety of manufactured products. Thus, if the manufacturing experience is used rationally, empirical regression models with high precision can be obtained that are particularly useful in improving the controlled lamination process. The more extensive the database, the more predictive power of regression empirical models becomes larger.

Predictive model of the mechanical properties of hotrolled thick sheets

Production of thick sheets by hot rolling

In this paper were used databases collected from the hot rolling process of the thick plates (Arcelor-Mittal Plant, Galati, Romania), using 2 quarto cages, according to figure 1. The selected steel grade, from the product portfolio, was S235J $R$, with variant S235J $R+A R$. 


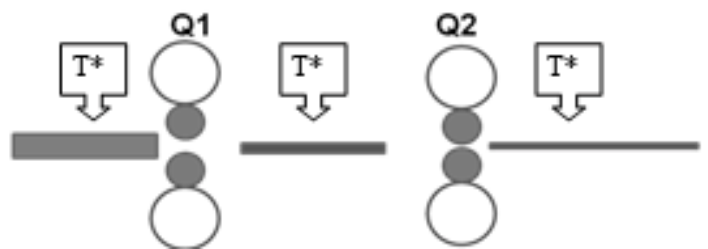

The controlled rolling cycle consists of hot plastic deformation using the next steps:

-heating the slab in the propulsion furnace,

-primary Q1 rolling through several combined passes changing the rolling direction to reach the prescribed width,

-keeping on the roller path between the two cages to reach a certain temperature,

-processing at Q2 through successive passes and ending the deformation under the conditions of reaching a precisely determined temperature.

Description of regression equations

The equations were obtained with the specialized application DATAFIT and are based on the data obtained by processing of 27 charges by S235J R+AR grade steel (approximately 50 tone of each charge) as thick sheets by various dimension. For this steel the chemical composition correspond to EN 10025:2004, and is presented in table 1
Fig.1 Schematic of the hot rolling process of thick slabs using two quarto cages' Q1-roughing mill quarto cage, Q2finishing mill quarto cage. $T^{*}$-temperature sensor and table 2 it refer mechanical properties according to thickness.

The variation range of the chemical composition of the slabs used to obtain the thick sheets, taken into account for regression, is as shown in table 3.

The input data:

-chemical composition (16 elements): C, Mn, Si, Al, B, $\mathrm{Mo}, \mathrm{N}, \mathrm{Nb}, \mathrm{Ti}, \mathrm{V}, \mathrm{Ni}, \mathrm{Cr}, \mathrm{Ca}, \mathrm{P}, \mathrm{S}, \mathrm{Cu}$;

-rolling conditions: temperature drop at Q1 cage-DT1, temperature loss between the two cages - DT12, total reduction of thickness at Q2 finishing cage -Dh2, and final temperature - $T f$,

The output data:

-ultimate tensile strength, $R m$

-yield strength, $R p_{0}$

-elongation at break, $A_{50}$

The best equations, in terms of prediction capacity, have been shown to be exponential, for all three mechanical features. Generic equations are by type:

$$
M P=\exp \left(\begin{array}{l}
a_{1} \cdot C+a_{2} \cdot M n+a_{3} \cdot S i+a_{4} \cdot A l+a_{5} \cdot B+a_{6} \cdot M o+a_{7} \cdot N+ \\
+a_{8} \cdot N b+a_{9} \cdot T i+a_{10} \cdot V+a_{11} \cdot N i+a_{12} \cdot C r+a_{13} \cdot C a+a_{14} \cdot P+a_{15} \cdot S+ \\
+a_{16} \cdot C u+a_{17} \cdot D T 1+a_{18} \cdot D T 12+a_{19} \cdot D h 2+a_{20} \cdot I f+a_{21}
\end{array}\right)
$$

for the identification of $M P$ (mechanical property) with $R_{m^{\prime}} R p_{02}$ and $A_{50}$ is used table 4 where the values of coefficients $a_{n}$.

Table 1

CHEMICAL COMPOSITIONS OF THE STEEL GRADE S235]

\begin{tabular}{|c|c|c|c|c|c|}
\hline $\begin{array}{c}\text { C max. } \\
{[\%]}\end{array}$ & $\begin{array}{c}\mathrm{Mn} \max . \\
{[\%]}\end{array}$ & $\begin{array}{c}\mathrm{P} \max . \\
{[\%]}\end{array}$ & $\begin{array}{c}\mathrm{S} \max . \\
{[\%]}\end{array}$ & $\begin{array}{c}\mathrm{N} \max . \\
{[\%]}\end{array}$ & Cu max. [\%] \\
\hline 0.17 & 1.40 & 0.035 & 0.035 & 0.012 & 0.40 \\
\hline
\end{tabular}

Table2

MECHANICAL PROPERTIES OF S235J R+AR GRADE STEEL

\begin{tabular}{|c|c|c|c|c|c|c|c|c|c|}
\hline \multicolumn{2}{|c|}{$\begin{array}{c}\text { Thick } \\
{[\mathrm{mm}]}\end{array}$} & $\begin{array}{c}\mathrm{Rm} \\
{\left[\mathrm{N} / \mathrm{mm}^{2}\right]}\end{array}$ & $\begin{array}{c}\text { Rpo2 min } \\
{\left[\mathrm{N} / \mathrm{mm}^{2}\right]}\end{array}$ & $\begin{array}{c}\text { As0 } \\
\text { long. } \\
{[\%]}\end{array}$ & $\begin{array}{c}\text { A\% } \\
\text { Transv. } \\
{[\%]}\end{array}$ & $\begin{array}{c}\text { KV 20 } \\
\text { long } \\
{[\mathrm{J}]}\end{array}$ & $\mathrm{HB}$ & \multicolumn{2}{|c|}{$\begin{array}{c}\text { E } \\
{[\mathrm{GPa}]}\end{array}$} \\
\hline & 3 & $360-510$ & 235 & & & & & 200 & 77 \\
\hline 3 & 16 & $360-510$ & 235 & 26 & 24 & 27 & $104-154$ & & \\
\hline 16 & 40 & $360-510$ & 225 & 26 & 24 & 27 & $104-154$ & & \\
\hline 40 & 63 & $360-510$ & 215 & 25 & 23 & 27 & $104-154$ & & \\
\hline 63 & 80 & $360-510$ & 215 & 24 & 22 & 27 & $104-154$ & & \\
\hline 80 & 100 & $360-510$ & 215 & 24 & 22 & 27 & $104-154$ & & \\
\hline 100 & 150 & $350-500$ & 195 & 22 & 22 & 27 & $103-159$ & & \\
\hline 150 & 200 & $340-490$ & 185 & 21 & 21 & 27 & $100-149$ & & \\
\hline 200 & 250 & $340-490$ & 175 & 21 & 21 & 27 & $100-149$ & & \\
\hline
\end{tabular}

Table3

RANGE OF THE CHEMICAL COMPOSITION FOR SLABS BY S235) R+AR, GRADE, USED TO ROLLED AS THICK SHEETS AND TAKEN IN CONSIDER TO OBTAIN THE REGRESSION EQUATIONS

\begin{tabular}{|c|c|c|c|c|c|c|c|c|c|c|c|c|c|c|c|c|}
\hline \multirow{2}{*}{ Range } & \multicolumn{16}{|c|}{ Chemical composition [\%] } \\
\hline & $\mathrm{C}$ & $\mathrm{Mn}$ & $\mathrm{Si}$ & $P$ & $\mathrm{~S}$ & Al & $\mathrm{Cu}$ & $\mathrm{Cr}$ & $\mathrm{Ni}$ & $\mathrm{V}$ & $\mathrm{M}$ & $\mathrm{Ti}$ & $\mathrm{Nb}$ & & $\mathrm{Ca}$ & $\mathrm{N}$ \\
\hline $\max$ & 0.158 & 1.156 & 03281 & 0.016 & 00141 & 0.0503 & 000219 & 00463 & 0.024 & 000026 & 0.0034 & 0.0187 & 0.038 & 0.0004 & 0.0005 & 0.0119 \\
\hline $\min$ & 0.0955 & 04842 & 0.0099 & 0.008 & 000025 & 0.0234 & 00097 & 00125 & 00054 & 0.001 & 0.0003 & 0.0006 & 0,0005 & 0.0001 & 0.0000 & 0.0042 \\
\hline
\end{tabular}


Table 4

THE COEFFICIENTS OF THE REGRESSION EQUATIONS FOR MECHANICAL PROPERTIES OF S235JR+AR GRADE STEEL

\begin{tabular}{|c|c|c|c|c|}
\hline $\begin{array}{c}\text { Independent } \\
\text { variables }\end{array}$ & $\begin{array}{c}\text { Coefficient } \\
\text { values }\end{array}$ & $\mathrm{R}_{\mathrm{m}}$ & $\mathrm{Rp}_{02}$ & $A_{50}$ \\
\hline$C$ & $a_{l}$ & 0.9602675731 & -3.647004438 & -1.098338771 \\
\hline$M n$ & $a_{2}$ & -0.6556718415 & 0.1567337987 & 0.494669794 \\
\hline Si & $a_{3}$ & -0.6492878106 & -0.5285326532 & -0.661594364 \\
\hline Al & $a_{4}$ & 16.78881809 & 4.116154845 & -22.07951011 \\
\hline$B$ & $a_{s}$ & -8.173500214 & 8.062270371 & -4.028283309 \\
\hline Mo & $a_{s}$ & 1.538285149 & -4.907307743 & 0.6915519253 \\
\hline$N$ & $a_{7}$ & -12.7258937 & 4.344420294 & 5.135114846 \\
\hline $\mathrm{Nb}$ & $a_{s}$ & -9.891038741 & -0.6450059851 & 11.44735446 \\
\hline$T i$ & $a_{p}$ & 22.10004937 & -13.58223789 & -18.36943513 \\
\hline$V$ & $a_{10}$ & 179.1150458 & -170.2428821 & 4.358126283 \\
\hline $\mathrm{Ni}$ & $a_{H}$ & 2.913917944 & 17.69123764 & -1.724012582 \\
\hline $\mathrm{Cr}$ & $a_{l 2}$ & 13.32867763 & 43.46711245 & -29.44364429 \\
\hline $\mathrm{Ca}$ & $a_{l 3}$ & 1.641087558 & -18.91475744 & 10.65286435 \\
\hline$P$ & $a_{14}$ & 71.88774592 & \begin{tabular}{|l|}
-314.3424388 \\
\end{tabular} & -141.553372 \\
\hline$S$ & $a_{l s}$ & 6.144181251 & 64.03997355 & -26.01190585 \\
\hline $\mathrm{Cu}$ & $a_{I G}$ & 110.0191745 & 642.8730529 & -50.39084957 \\
\hline$D T 1$ & $a_{17}$ & 0.002574753692 & 0.004285270873 & -0.00131941851 \\
\hline DT12 & $a_{l s}$ & 0.003324563715 & 0.003429612622 & 0.0003598947136 \\
\hline Dh2 & $a_{l g}$ & 0.001553452351 & 0.0008226476719 & 0.0002659713233 \\
\hline If & $a_{30}$ & 0.003556142057 & -0.0008773380134 & -0.00554579267 \\
\hline- & $a_{I I}$ & 5.330485206 & 5.38930838 & 3.957962731 \\
\hline
\end{tabular}

In order to mark the capacity of the chemical elements in influencing the mechanical characteristics, in first stand, the equations without the thermo-mechanical factors of influence were used, and the obtained results are presented in figure 2. Then, a chemical element of the next following 10 was abandoned: N, Ca, B, Nb, Ti, Mo, V, Ni, Cr and Al. At each extraction of one element, all 15 remaining elements of the total of 16 were considered. Obtained values for the of multiple determination coefficient $\left(R^{*}\right)$ are those in table 4. For each of the mechanical features are marked by writing in bold the extreme, minimum and maximum values of $R^{*}$. In the graphical representations of figures 2, 3 and 4 , associated with table 3 , one can observe the influence of each of the 10 chemical elements taken into account in the mechanical properties. The bars corresponding to each chemical element have the larger gray color side at the more of the influence on the property is stronger.

By including in the regression equations all 20 independent variables, 16 alloy elements and 4 thermomechanical parameters that refer to the actual rolling process, the predictive capacity of the mechanical

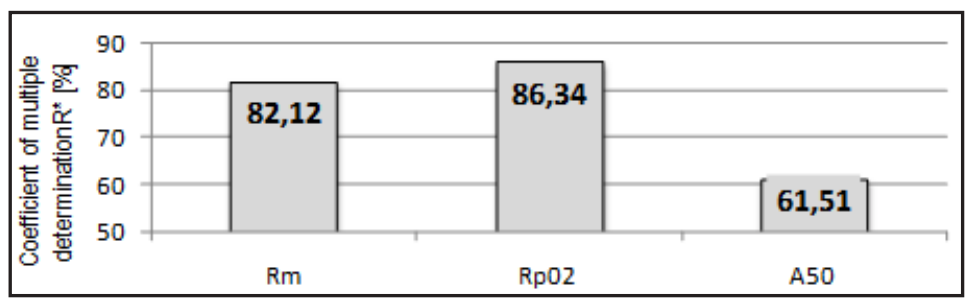

Fig. 2 Influence of all (16) alloying elements concentration on the prediction power of the regression equation, for breaking strength, $\mathrm{Rm}, \mathrm{Rp}_{02}$ and $A_{50}$, expressed by the value of the coefficient by multiple determination, $\mathrm{R}^{*}$

\begin{tabular}{|c|c|c|c|c|}
\hline \multicolumn{2}{|c|}{ Element } & $\begin{array}{c}R^{*} \text { for } \mathrm{Rm} \\
{[\%]}\end{array}$ & $\begin{array}{c}R^{*} \text { for } R p_{02} \\
{[\%]}\end{array}$ & $\begin{array}{c}R^{*} \text { for Aso } \\
{[\%]}\end{array}$ \\
\hline \multicolumn{2}{|c|}{ ALL (16) } & 82.12 & 86.34 & 61.51 \\
\hline \multirow{10}{*}{ 志 } & $\mathrm{N}$ & 79.89 & 85.18 & 60.17 \\
\hline & $\mathrm{Ca}$ & 81.67 & 86.15 & 60.71 \\
\hline & $B$ & 79.69 & $86.34^{\min }$ & 61.25 \\
\hline & $\mathrm{Nb}$ & 81.6 & 83.88 & 58.89 \\
\hline & $\mathrm{Ti}$ & $82.09^{\min }$ & 83.46 & $57.72^{\max }$ \\
\hline & Mo & 79.10 & 86.24 & 60.40 \\
\hline & $\mathrm{V}$ & 77.53 & $77.01^{\max }$ & 59.79 \\
\hline & $\mathrm{Ni}$ & 79.24 & 86.27 & 61.32 \\
\hline & $\mathrm{Cr}$ & 82.04 & 85.22 & $61.35^{\min }$ \\
\hline & $\mathrm{Al}$ & $76.15^{\max }$ & 82.28 & 61.25 \\
\hline
\end{tabular}

Table 5

MULTIPLE DETERMINATION COEFFICIENT ( $R *$ ) VALUES OBTAINED BY RENOUNCING ONE CHEMICAL ELEMENT, IN THE REGRESSION EQUATIONS OF THE THREE MECHANICAL PROPERTIES 


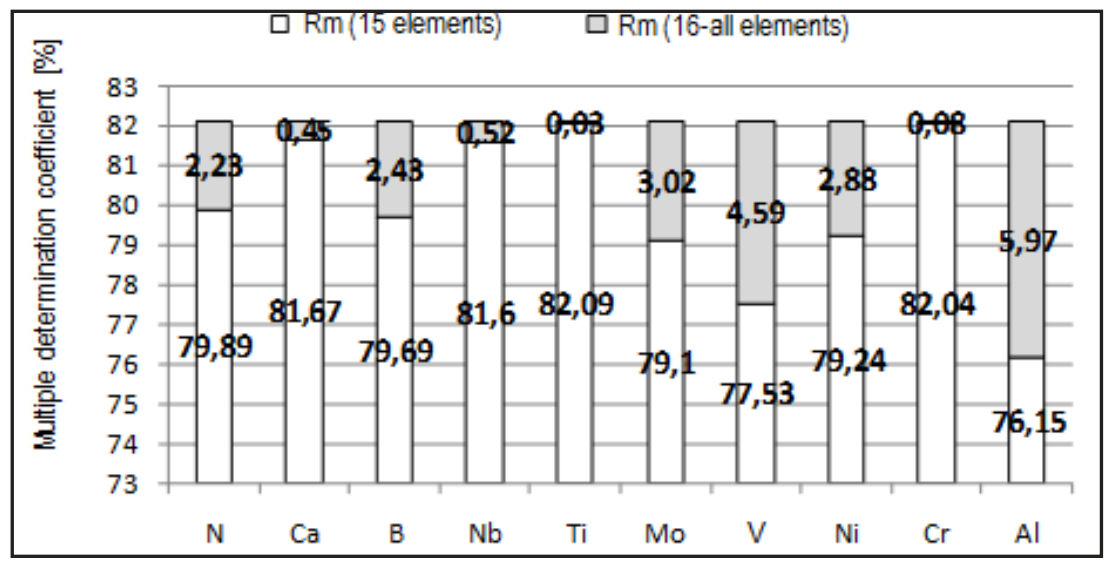

Chemical element [\%]
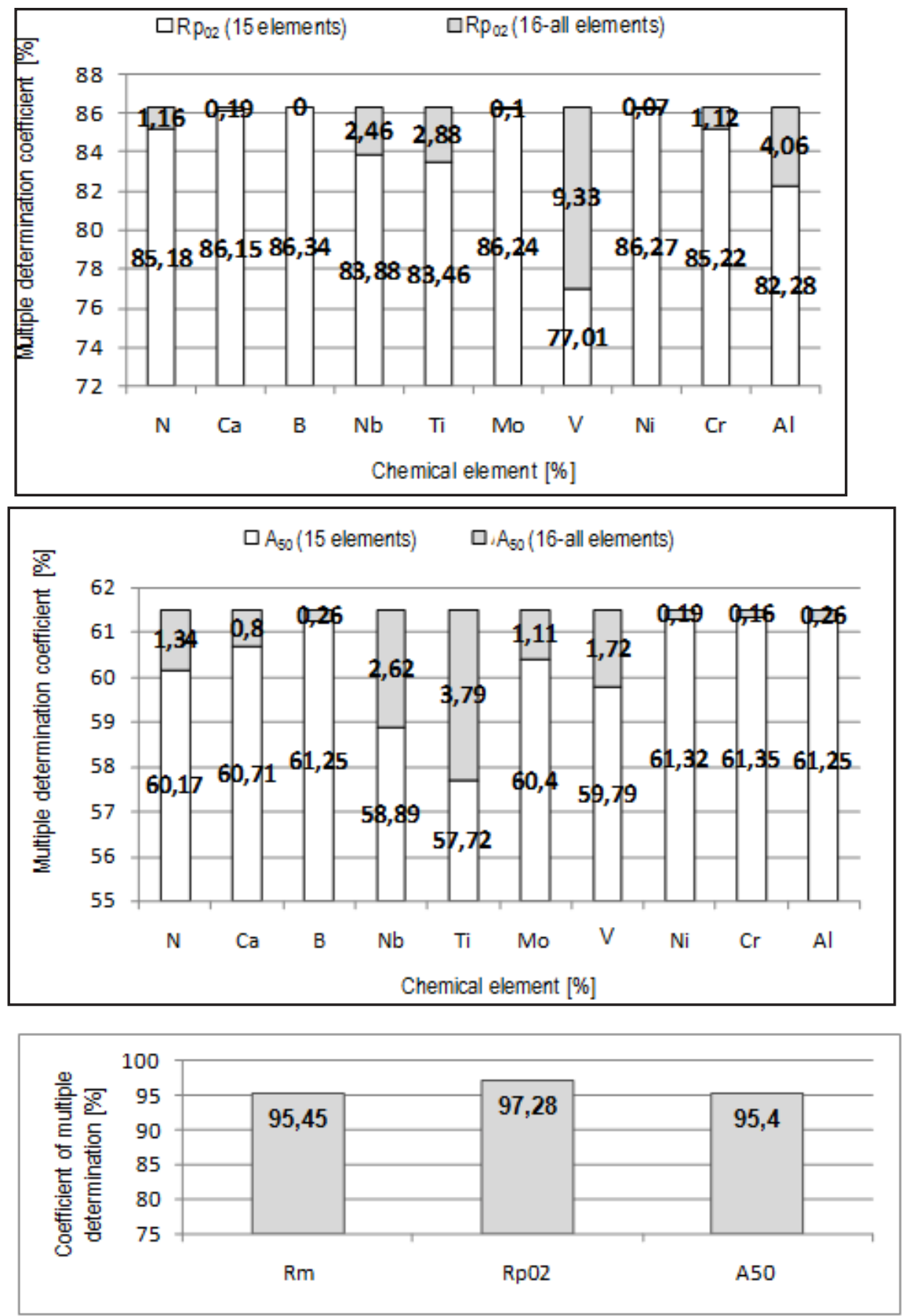

Fig. 3 Influence of alloying elements concentration on the prediction power of the regression equation, for breaking strength, $\mathrm{Rm}$, expressed by the value of the coefficient by multiple determination, $\mathrm{R}^{*}$

Fig. 4 Influence of alloying elements concentration on the prediction power of the regression equation, for yield strength, $\mathrm{Rp}_{02}$ expressed by the value of the coefficient by multiple determination, $\mathrm{R}^{*}$
Fig. 5 Influence of alloying elements concentration on the prediction power of the regression equation, for elongation at break, $A_{50^{\prime}}$ expressed by the value of the coefficient by multiple determination, $\mathrm{R}^{*}$
Fig. 6 The predictive capacity of the regression equations for the mechanical properties of S235J + AR thick steel sheets according to 16 alloying elements and 4 thermo-mechanical parameters of the rolling processing expressed by the coefficient by multiple determination, $\mathrm{R}^{*}$ properties has grown very consistently, as can be seen in figure 6 .

The use of prediction regression equations of mechanical properties of S235J $R+A R$ thick steel sheets to optimize the controlled rolling process

By using high predictive regression equations, an algorithm for calculating mechanical properties was assembled, depending on the thermo-mechanical parameters of the lamination, for a slab with a certain chemical composition. This is the situation that is common in practice. By lamination, thick sheets have to be made to meet the requirements relating to mechanical properties as well. Based on this algorithm using the MATLAB engineering application package, a set of instructions has 


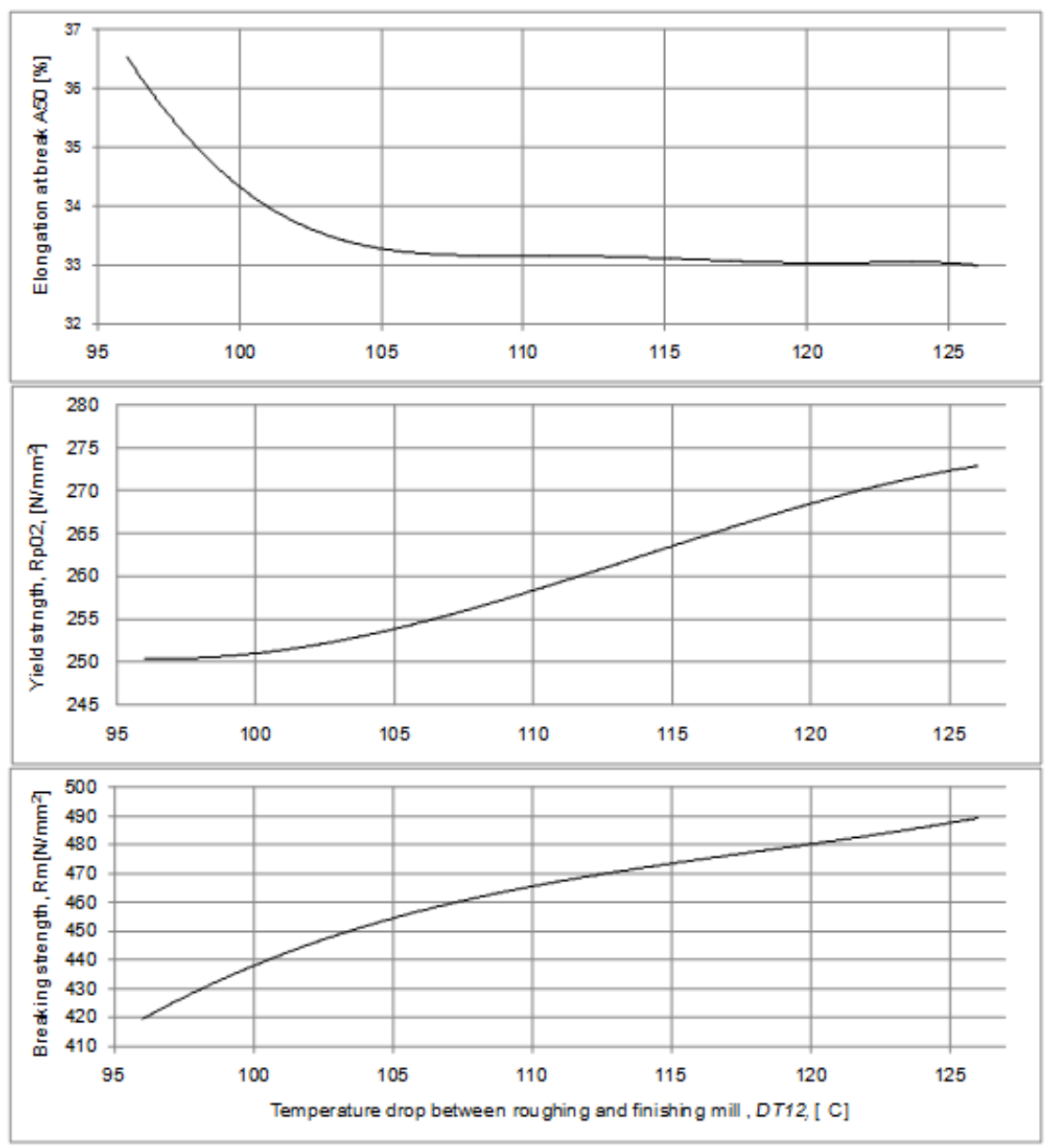

Fig. 7 The predictive capacity of the regression equations for the mechanical properties of S235J + AR thick steel sheets according to 16 alloying elements and 4 thermomechanical parameters of the rolling processing expressed by the coefficient by multiple determination, $\mathrm{R}^{*}$

been written, which allows the optimization of the rolling regime with respect to desired mechanical properties.

For example, for an average chemical composition in the composition field of the 27 charges that constituted the database (for each of the 16 elements considered), keeping constant :the temperature of the slab heating, the temperature drop , DT1, at roughing mill, temperature drop at finishing mill, DT2, deformation at finishing mill, Dh2, and temperature at the end of deformation, $\mathrm{Tf}$, and vary only temperature drop, across the path between the two cages, DT12, the mechanical properties shown in $\mathrm{f}$ igure 7 are obtained.

\section{Conclusions}

A. In order to correlate the chemical composition and the thermo-mechanical rolling parameters with the main mechanical characteristics, in the case of thick steel sheets S235J $R+A R$, a set of high predictive regression equations were obtained, expressed by the coefficients of multiple determination, $R^{*}: 95.45 \%, 97.28 \%$ and $95.4 \%$ for $\mathrm{Rm}, \mathrm{Rp02}$ and $A 50$, respectively;

$B$. By using the regression relations we have identified the chemical elements that have an extreme influence on the mechanical properties, as follows:- $R m-A l, R p_{02}-V$ and $A_{50}-T i$, are in relationships of maximum dependence;

$-R m-T i, R p_{02}-B$ and $A_{50}$-Crare in minimum dependence relationships;

C. An empirical mathematical model, based on the regression equations, for the mechanical characteristics $R m, R p 02$ and A50, which has been translated into MATLAB-specific instructions, has been designed to simulate the rolling process and to find the optimum variant to achieve the desired mechanical properties.

Detailed data bases, which are made at the level of a thick steel sheet producer, are very useful to improve the degree of product compliance, in terms of mechanical characteristics, achieved by controlled lamination with the strict requirements of norms and standards.

\section{References}

1.SAITO, Y., SAEKI, M., NISHIDA, M., ITO, Y., TANAKA, T., TAKIZAWA, S., Proc. Int. Conf. Steel Rolling, ISIJ, Tokyo, 1980, p. 130.

2.ESAKA, K., WAKITA, J., TAKAHASHI, M., KAWANO, O., HARADA, S., Seitetsu-Kenkyu, nr. 321, 1986, p. 92.

3.SAITO, Y., SHIGA, C., ENAMI, T., THERMEC-88, ISIJ , Tokyo, 2, 1988, p. 753;

4. JAISWAL, S., McIVOR, I.D., Ironmaking and Steelmaking, nr. 16, 1989, p. 49

5.PURCELL, A., Mathematical Modelling of Temperature Evolution in the Hot Rolling of Steel, Master Thesis, Department of Mining and Metallurgical Engineering McGil1 University, Montreal, 2000.

6. WARDE, J., KNOWLES, D. M. Application of Neural Networks to Mechanical Property Determination of Ni-base Superalloys, ISIJ International, nr. 39, 1999, p. 1006.

7.SINGH, S., BHADESHIA, H.K.D.H., MACKAY, D., CAREY, H. MARTIN, I., Neural network analysis of steel plate processing, Ironmaking and Steelmaking, nr. 25, 1998, p. 355.

8.A RAVOIU, L BENEA, A CHIRIAC, Metabolic Albumin and Its Effect on Electrochemical Behavior of Titanium Implant Alloy, Materials Science and Engineering 374 (2018) 012077, doi:10.1088/1757-899X/ 374/1/012077.

9.D. L. BURUIANA, G. L. TIRON, S. PINTILIE, C. S. SIMIONESCU, S. BALTA, Influence Of The TiO2 And Zno Nanoparticles On The Permeation Properties Of Psf Membranes, Revista Romana de Materiale nr 4. 2015, pp354-357.

10.RYU, J.H., Model for Mechanical Properties of Hot-Rolled Steels, Master thesis, Department of Ferrous Technology, Pohang University of Science and Technology, 2008

Manuscript received: 7.12 .2018 